\title{
Validity Study of the Roll-Over Test and Risk Factors for Preeclampsia in Four Health Districts of Surigao City, Philippines
}

\author{
Lovella C. Condeza, ${ }^{1}$ Christopher B. Arguelles, ${ }^{2,3}$ Cris F. Velez, ${ }^{4}$ Glenda M. Labadan, ${ }^{4}$ \\ Emmanuel S. Baja ${ }^{5,6}$ and Godofreda Vergeire-Dalmacion ${ }^{5,6,7}$ \\ ${ }^{1}$ Research, Planning and Development Office, Surigao Education Center, Surigao, Philippines \\ ${ }^{2}$ Office of the Quality Management, Surigao Education Center, Surigao, Philippines \\ ${ }^{3}$ Department of Electrical Engineering, Surigao Education Center, Surigao, Philippines \\ ${ }^{4}$ Department of General Education, Surigao Education Center, Surigao, Philippines \\ ${ }^{5}$ Department of Clinical Epidemiology, College of Medicine, University of the Philippines Manila, Manila, Philippines \\ ${ }^{6}$ Institute of Clinical Epidemiology, National Institutes of Health, University of the Philippines Manila, Manila, Philippines \\ 'Department of Pharmacology and Toxicology, College of Medicine, University of the Philippines Manila, Manila, Philippines
}

\section{ABSTRACT}

Background. The roll-over test is a simple, easily available clinical test using the sphygmomanometer to predict pregnancy-induced hypertension starting at 20 weeks age of gestation (AOG). However, the roll-over test is not part of the standard prenatal care in government health facilities even if health workers can easily perform the test.

Objectives. To validate the roll-over test at the $20^{\text {th }}$ weeks of gestation and to determine the risk factors for preeclampsia in 4 health districts of Surigao City, a province in the CARAGA Region of the Philippines.

Methods. A total of 190 pregnant women without history of hypertension during their previous pregnancies from 4 health districts in Surigao City, Philippines were consecutively enrolled from May 2014 to October 2014 in a cross-sectional study design. The roll-over test was done using the method described in Williams Obstetrics and the validity of the roll-over test was measured. Bivariate and multivariate analyses were done to determine risk factors for preeclampsia.

Results. Seven of the 190 women developed preeclampsia. The sensitivity of the rollover test done at 20 weeks AOG was $43 \%$ and the specificity was $81 \%$. Maternal age, history of urinary tract infection (UTI) and a positive rollover test were associated with preeclampsia.

Conclusion. Pregnant women whose ages are $<20$ years or $>29$ years old, or who had a history of UTI, or a positive roll-over test are more likely to develop preeclampsia. Roll-over test has a low sensitivity at 20 weeks AOG. More studies are warranted to explore the improvement of its predictive value in other AOG.

Key Words: age of gestation, preeclampsia, pregnant women, risk factors, roll-over test

\section{INTRODUCTION}

A pervasive global health problem targeted by the World Health Organization Millennium Development Goal (MDG) was the reduction of Maternal Mortality Rate

Corresponding author: Godofreda Vergeire-Dalmacion, MD, MSc Pharmacoepidemiology, MHPEd

Department of Pharmacology and Toxicology

College of Medicine

University of the Philippines Manila

547 Pedro Gil St., Ermita, Manila 1000, Philippines

Telephone: +63917 8408556

Email: jody.dalmacion@gmail.com
(MMR) by the year 2015..$^{\circ}$ In the CARAGA region of the Philippines, this was translated to a $75 \%$ reduction of its MMR from 161/100,000 live births in 1991 to 40/100,000 live births by $2015 .{ }^{2}$ The CARAGA Region (Region XIII) is the newest region of the Philippines. It is composed of 5 provinces including Surigao. ${ }^{3}$ Data in 2010 from the CARAGA Regional Hospital of Surigao City reported 
4 cases of mothers who died during childbirth, which increased to 9 cases in 2011. The 2011 Health Statistics of the Department of Health-Center for Health Development reported preeclampsia $(\mathrm{PE})$ as second leading cause of maternal mortality in the Philippines next to post-partum haemorrhage. The CARAGA Regional Hospital in 2011 reported 122 cases of eclampsia. Within the first 9 months of 2012, health centers from Surigao had already reported and subsequently referred 17\% (94/548) of pregnancies with elevated blood pressure to the CARAGA Regional Hospital. ${ }^{2}$

A systolic blood pressure of more than $140 \mathrm{~mm} \mathrm{Hg}$ and a diastolic blood pressure of more than $90 \mathrm{~mm} \mathrm{Hg}$ on a previously normotensive pregnant woman plus protein in the urine of more than $300 \mathrm{mg}$ in 24 hours or more than +1 or +2 on dipstick with or without edema are clinical hallmarks for the diagnosis of preeclampsia syndrome. ${ }^{4}$ However, a recent review by Lindheimer and Kanter pointed out that there are no strong data to support the $300 \mathrm{mg} / 24$-hour cutoff commonly used to diagnose preeclampsia. ${ }^{5}$ Likewise, the recent guideline of the American College of Obstetrician (ACOG) on hypertension during pregnancy does not require high levels of protein in the urine as a basis for diagnosing preeclampsia. It is recommended for physicians to consider other factors in addition to elevated blood pressure to diagnose preeclampsia. ${ }^{6}$

Preeclampsia occurs in about $2 \%$ to $8 \%$ of pregnancies after mid-gestation. ${ }^{7-8}$ It is the most common medical complication of pregnancy whose incidence has continued to increase worldwide. ${ }^{9}$ More importantly, preeclampsia is associated with significant maternal morbidity and mortality, accounting for about 50,000 deaths worldwide annually. ${ }^{9}$ Several factors have been previously incriminated as predisposing to the development of preeclampsia, namely age of the mother, previous preeclampsia, family history of preeclampsia, multiple pregnancy, pre-existing medical condition: insulin dependent diabetes, chronic hypertension, renal disease, autoimmune disease, antiphospholipid syndrome, parity, time between pregnancies, period of sexual cohabitation before pregnancy, maternal physical activity during pregnancy, previous abortions, miscarriages and stress. ${ }^{10-11}$ Early detection of preeclampsia will allow for more intensive antenatal surveillance, early management to avert complications such as seizure, cardiovascular and metabolic complications and even death. Screening pregnant women who are likely to develop preeclampsia during the course of their pregnancies is still the subject of many researches. ${ }^{12}$ The National Institute of Clinical Excellence in the United Kingdom proposed a screening strategy based on maternal history and other risk factors. It was able to classify more than $60 \%$ of pregnant women as high risk and predicted less than $30 \%$ of those likely to develop preeclampsia. ${ }^{12}$ Recent advances investigating the best strategy for predicting preeclampsia affirmed the need of not a single but a combination of two or more independent biomarkers or predictors and inclusion of other tests together with uterine artery Doppler to achieve a high sensitivity and acceptable specificity for screening of preeclampsia. ${ }^{13}$ Despite these advances, local health providers practicing in the community are still beset with limited health resources while their patients suffer from limited access to highly technology-based screening tests. This study analyzed the associations between several risk factors and preeclampsia in 4 health districts of Surigao City, Philippines and reassessed the validity of the roll-over test to screen women who will develop preeclampsia in the course of their pregnancies in a resource challenged community-based setting.

\section{METHODS}

\section{Study Population}

Surigao, one of the provinces in CARAGA in the Island of Mindanao, has a population of 154,137. The CARAGA region is served by three hospitals of which the Regional Hospital provides many inpatient and outpatient services to the residents of the area. ${ }^{3}$ A cohort of 190 pregnant women was consecutively recruited in their $20^{\text {th }}$ week of gestation from 4 health districts in the towns of San Juan, Washington, Taft and Luna. Enrollment was done from May 2014 to October 2014. Women with a previous history of preeclampsia, pre-existing hypertension, intake of aspirin or any vasoactive drugs, and inability to sign an informed consent were excluded from the study. The study had institutional ethics review board approval.

After obtaining an informed consent from the pregnant women attending the 4 health districts, an intervieweradministered questionnaire was used to obtain data on the age of the patient, occupation, education, socio-income group and other exposure variables such as smoking, medical history of Urinary Tract Infection (UTI), family history of preeclampsia, use of condiments or seasoning. The interviewers were members of the research team and spoke the dialect of the region. Thus, barriers related to familiarity of the interviewers to local customs and the dialect of the region were effectively overcame.

\section{Roll-Over Test Measurement}

All women who were eligible for inclusion subsequently underwent the roll-over test. They were asked to lie on their left side for 5 minutes and their blood pressure measured by a Baumann's sphygmomanometer. Two measurements were done until a stable reading is observed after which they were asked to lie on a supine position. Blood pressure was immediately measured by the same examiner and repeated after 5 minutes. An increase of $15 \mathrm{mmHg}$ or more in the systolic pressure or an increase of $10 \mathrm{mmHg}$ or more in the diastolic pressure was considered a positive roll-over test. ${ }^{14}$

\section{Health Outcome - Preeclampsia Measurement}

Diagnosis of preeclampsia was taken from the records of the four health districts, CARAGA Regional Hospital and some private birthing homes where the participants indicated the places of delivery. 


\section{Statistical Analysis}

Descriptive statistics for study characteristics of the participants, as well as correlation coefficients to evaluate their relationships, were calculated. In addition, sensitivity, specificity, positive predictive value (PPV), and negative predictive value (NPV) of the roll-over test were also calculated.

Bivariate and multivariate analyses of the associations between preeclampsia and all the possible risk factors were examined. Bivariate logistic regression model was used to estimate crude odds ratios (ORs) with 95\% confidence intervals (95\% CIs) while multivariate logistic regression model was used to estimate the adjusted odds ratios (AORs) with $95 \%$ CIs. Maternal age ( $<20,20-29, \geq 30$ years), monthly income ( $<5,000$ pesos vs. $\geq 5,000$ pesos), occupation (employed vs. unemployed), education (college level or higher vs. high school graduate or lower), cigarette smoking status (never vs. ever), use of condiments or seasoning (user vs. non-user), medical history of UTI (with vs. without), family history of preeclampsia in a first-degree relative (known vs. unknown), and roll-over test (positive vs. negative) were included into the multivariate logistic regression model. These variables were chosen a priori as potentially risk factors of preeclampsia.

Table 1. Characteristics of Study Population ( $n=190)$

\begin{tabular}{|c|c|}
\hline Characteristics & Value \\
\hline \multicolumn{2}{|l|}{ Maternal age, years old (\%) } \\
\hline$<20$ & 20.5 \\
\hline $20-29$ & 54.2 \\
\hline$\geq 30$ & 25.3 \\
\hline \multicolumn{2}{|l|}{ Combined monthly income (\%) } \\
\hline Below Php 5,000.00 & 32.6 \\
\hline Php 5,000.00 and above & 67.4 \\
\hline \multicolumn{2}{|l|}{ Occupation (\%) } \\
\hline Employed & 13.7 \\
\hline Unemployed & 86.3 \\
\hline \multicolumn{2}{|l|}{ Highest educational attainment (\%) } \\
\hline College level or higher & 26.8 \\
\hline High school graduate or lower & 73.2 \\
\hline \multicolumn{2}{|l|}{ Cigarette smoking status (\%) } \\
\hline Ever smoker & 9.5 \\
\hline Never smoker & 91.5 \\
\hline \multicolumn{2}{|l|}{ Use of condiments or seasonings (\%) } \\
\hline User & 91.1 \\
\hline Non-user & 8.9 \\
\hline \multicolumn{2}{|l|}{ Roll-overtest(\%) } \\
\hline Positive & 19.5 \\
\hline Negative & 80.5 \\
\hline \multicolumn{2}{|l|}{ Medical history (\%) } \\
\hline With urinary tract infection & 60.5 \\
\hline Without urinary tract infection & 39.5 \\
\hline \multicolumn{2}{|l|}{ Family history of preeclampsia (\%) } \\
\hline Sister & 8.4 \\
\hline Mother & 7.9 \\
\hline
\end{tabular}

Effect estimates were reported as crude $\mathrm{OR}$ and adjusted OR for preeclampsia. Likelihood ratio test was used to test the significance of the variables. P-value of $\leq 0.05$ was considered to be statistically significant. $R$ (version 3.2.1; R Foundation for Statistical Computing 2013, http://www.r-project.org) was used in all the logistic regression analyses.

\section{RESULTS}

A total of 190 eligible patients were included in the study. Table 1 shows the characteristics of research participants of which $54 \%$ belonged to the 20-29 years old age group and $67 \%$ had a combined monthly income of $5,000.00$ pesos or above. Most were unemployed (87\%), never smoked (90\%) and almost all were users of condiments or seasonings (91\%). About eighty percent were negative for the roll-over test.

Only 7 (4\%) of the 190 participants were diagnosed at the time of delivery with preeclampsia. Three of the seven participants belonged to the $\geq 30$ years old age group and had a combined monthly income of below Php 5,000.00, and 5 of the 7 pregnant women were unemployed (Table 2). Three of the 7 participants who developed preeclampsia were

Table 2. Cases of Preeclampsia $(\mathrm{N}=7)$

\begin{tabular}{|c|c|}
\hline Characteristics & No. of Preeclampsia Cases \\
\hline \multicolumn{2}{|l|}{ Maternal age, years old } \\
\hline$<20$ & 2 \\
\hline $20-29$ & 2 \\
\hline$\geq 30$ & 3 \\
\hline \multicolumn{2}{|l|}{ Combined monthly income } \\
\hline Php 5,000.00 and above & 4 \\
\hline Below Php 5,000.00 & 3 \\
\hline \multicolumn{2}{|l|}{ Occupation } \\
\hline Employed & 2 \\
\hline Unemployed & 5 \\
\hline \multicolumn{2}{|l|}{ Education } \\
\hline College level or higher & 4 \\
\hline High school graduate or lower & 3 \\
\hline \multicolumn{2}{|l|}{ Cigarette smoking status } \\
\hline Ever smoker & 0 \\
\hline Never smoker & 7 \\
\hline \multicolumn{2}{|l|}{ Use of condiments or seasonings } \\
\hline User & 5 \\
\hline Non-user & 2 \\
\hline \multicolumn{2}{|l|}{ Roll-over test } \\
\hline Positive & 3 \\
\hline Negative & 4 \\
\hline \multicolumn{2}{|l|}{ Medical history } \\
\hline With urinary tract infection & 3 \\
\hline Without urinary tract infection & 4 \\
\hline \multicolumn{2}{|l|}{ Family history of preeclampsia } \\
\hline Known (Sister/Mother) & 1 \\
\hline Unknown & 6 \\
\hline
\end{tabular}


positive for the roll-over test giving a sensitivity of $43 \%(3 / 7)$ and specificity of $81 \%(149 / 183)$. The PPV of the roll-over test was $8 \%$ (3/37), while the NPV was 97\% (149/153).

In the bivariate logistic regression analyses, several factors were positively associated with preeclampsia. First, having a positive rollover test $[\geq 15 \mathrm{~mm} \mathrm{Hg}$ (Systolic) or $\geq 10$ $\mathrm{mm} \mathrm{Hg}$ (Diastolic)] was associated with preeclampsia (OR: 3.3 with 95\% CI: 0.6-15.6). Second, maternal age > 29 years old was also associated with preeclampsia (OR: 3.4 with $95 \%$ CI: 0.5-26.2). However, these factors were not statistically significant (Table 3).

In the multivariate logistic regression model, a positive roll-over test (AOR: 7.3,95\% CI: 1.0 - 71.5) was statistically associated with preeclampsia. However, not all of the study characteristics of the participants were statistically significant, but participants with maternal age of $<20$ (AOR: 6.9, 95\% CI: $0.6-94.5$ ) or $\geq 30$ years old (AOR: $4.8,95 \%$ CI: 0.6-47.1), or with a college level education or higher (AOR: 5.0, 95\% CI: 0.9-35.2), or with employment (AOR: 4.7, 95\% CI: 0.4-48.2), or an ever smoker (AOR: $2.2,95 \%$ CI: 0.120.5), or with a medical history of UTI (AOR: 2.6, 95\% CI: 0.3-23.5) were also related to preeclampsia (Table 3).

\section{DISCUSSION}

Major causes of deaths in women are related to pregnancy and childbirth. One of these conditions is preeclampsia, which is a pregnancy-specific syndrome that virtually affects all organ system and accounts for approximately $12 \%$ of maternal deaths in the Philippines. ${ }^{15}$ Preeclampsia occurs approximately in $7 \%$ of first pregnancies and it is a major contributor to maternal and prenatal morbidity. In this study, $4 \%$ of the participants from the 4 health districts of Surigao City have preeclampsia. This prevalence of preeclampsia is in close agreement with results of other studies. ${ }^{16-19}$ The slight difference in the prevalence could be due to the small study population. From an extensive and comprehensive literature search, this is the first study on preeclampsia in the region of CARAGA. Nevertheless, larger studies are needed to validate the best cut-off for the AOG during which time, the roll-over test could accurately rule out the diagnosis of preeclampsia in pregnant women living in a resource-limited area such as a rural setting. A study in 1977 by Marshall and Newman done among 100 randomly selected nulliparous women at 28 to 32 weeks AOG showed none of the 75

Table 3. Crude and Adjusted Odds Ratios of Risk Factors for Preeclampsia

\begin{tabular}{|c|c|c|}
\hline Characteristics & Crude Odds Ratio (95\% Cl) & Adjusted Odds Ratio (95\% Cl) \\
\hline \multicolumn{3}{|l|}{ Maternal age, year old } \\
\hline$<20$ & $2.73(0.32-23.42)$ & $6.22(0.57-83.79)$ \\
\hline $20-29$ & 1.00 & 1.00 \\
\hline$\geq 30$ & $3.37(0.54-26.22)$ & $4.73(0.63-46.79)$ \\
\hline \multicolumn{3}{|l|}{ Combined monthly income } \\
\hline Below Php 5,000.00 & $1.58(0.30-7.37)$ & $2.63(0.41-18.88)$ \\
\hline Php 5,000.00 + & 1.00 & 1.00 \\
\hline \multicolumn{3}{|l|}{ Occupation } \\
\hline Employed & $2.65(0.37-13.08)$ & $3.72(0.32-37.33)$ \\
\hline Unemployed & 1.00 & 1.00 \\
\hline \multicolumn{3}{|l|}{ Education } \\
\hline College level or higher & $3.86(0.82-20.19)$ & $4.81(0.83-33.11)$ \\
\hline High school graduate or lower & 1.00 & 1.00 \\
\hline \multicolumn{3}{|l|}{ Cigarette smoking status } \\
\hline Ever smoker & $0.61(0.10-11.96)$ & $0.47(0.05-10.73)$ \\
\hline Never smoker & 1.00 & 1.00 \\
\hline \multicolumn{3}{|l|}{ Use of condiments or seasoning } \\
\hline User & $0.22(0.04-1.65)$ & $0.12(0.01-1.19)$ \\
\hline Non-user & 1.00 & 1.00 \\
\hline \multicolumn{3}{|l|}{ Roll-over test } \\
\hline Positive [ $\geq 15$ mm Hg (systolic) or $\geq 10$ mm Hg (diastolic)] & $3.29(0.62-15.58)$ & $7.19(1.00-69.92)$ \\
\hline Negative [<15 mm Hg (systolic) or $<10$ mm Hg (diastolic)] & 1.00 & 1.00 \\
\hline \multicolumn{3}{|l|}{ Medical history } \\
\hline With urinary tract infection & $1.16(0.22-5.39)$ & $2.38(0.33-21.29)$ \\
\hline Without urinary tract infection & 1.00 & 1.00 \\
\hline \multicolumn{3}{|l|}{ Family history of hypertension } \\
\hline Known (Sister/Mother) & $0.85(0.04-5.23)$ & $0.84(0.03-8.45)$ \\
\hline Unknown & 1.00 & 1.00 \\
\hline
\end{tabular}


participants with a negative roll-over test $(10 \%$ false-negative rate) developed preeclampsia. The study recommended that the roll-over test be a routine test for every pregnant patient between 28 and 32 weeks gestation for the early diagnosis of hypertension of pregnancy. ${ }^{20}$ It is surmised that advocating for the performance of the roll-over test later at 28 weeks AOG instead of at 20 weeks AOG as in this study might improve the validity of the test.

This study also shows that mothers who are $<20$ years of age and $\geq 30$ years old are 5 to 7 times more likely to develop preeclampsia compared to the 20-29 age group. Results concur with the findings of Wallis et al., which confirmed that the maternal age groups of $<20$ and $\geq 30$ years were greater risk factors for developing preeclampsia than 20-29 years of age. ${ }^{15}$ The mechanism behind the increased risk for women in the age group of $\geq 30$ years is not yet fully understood. ${ }^{21}$ According to Lamminpaa et al., the risk may be related to aging of the uterine blood vesse $\mathrm{l}^{22}$ or confounded by a pre-existing hypertension before the pregnancy. ${ }^{23}$ Although not statistically significant, this study shows that presence of a history of UTI increases the risk of pregnant women of developing preeclampsia by 3 times. It was hypothesized that renal damage related to preeclampsia may also underlie the patient's predilection to kidney infections..$^{24-25}$ The study of Minassian et al. showed the increased risk of late trimester preeclampsia following an incident of UTI or antibiotic prescription in the first two trimesters, which further supports the observed relationship between kidney infection and preeclampsia. ${ }^{26}$ Since maternal mortality is of public health concern, reducing its incidence together with child mortality can be one of the most effective strategies for reducing deaths among women in the reproductive age group and achieving the MDG goal even beyond the target year of 2015. Identification of women at risk for preeclampsia is of major importance, which according to the ACOG is associated with future cardiovascular and metabolic diseases in women. Women with a history of preeclampsia have a 1.5 to 2 times higher risk of developing heart diseases later. ${ }^{6}$ Prevention of these disastrous outcomes is now a target of intervention for the hypertensive pregnant women in the form of aspirin and calcium despite mixed effects. ${ }^{5}$

Regarding the roll-over test, data in this study shows a seven-fold higher risk of developing preeclampsia for those who are positive to the test. The roll-over test is one of the three provocative pressor tests, which also include the isometric exercise test and the Angiotension II infusion test to assess placental perfusion and vascular resistance in the uterine vessels during pregnancy. ${ }^{14}$ All of these tests measure the hypertensive response to stimuli manifested as an increase in blood pressure. However, these tests were considered inaccurate and unreliable with sensitivities ranging from $55 \%$ to $70 \%$ and specificities of $80 \%{ }^{12,14,27-28}$ In this study, the roll-over test has a sensitivity of $43 \%$ and a specificity of $81 \%$, values that are close to those in the cited literature. ${ }^{12,27-28}$
Based on review of the literature from 1990 onward, this study is the first locally-conducted investigation on the validity of the roll-over test among Filipino pregnant women. A much earlier study conducted in 1997 at Sao Paolo, Brazil by Marcopito et al. involving 369 pregnant women revealed a much lower sensitivity of the roll-over test at $20 \%(7 / 35)$ and a specificity of $93 \%(311 / 334) .^{29}$

No maternal deaths or serious complications was observed during the duration of this study. However, a major limitation is the higher probability of suffering from a confounding factor bias being a cross-sectional study compared to a repeated measure or longitudinal study design. Bias due to residual or unmeasured confounding factors cannot also be ruled out. Because the study population consists of Filipino women, the results may not be generalizable to women of other racial and ethnic groups. However, the setting may be applicable to other rural areas in the Philippines. The current classification of preeclampsia to early and late onset also suggests that repeated roll-over test after the $20^{\text {th }}$ weeks AOG may increase its sensitivity and specificity. Nevertheless, it is obvious that more studies are needed to validate the findings from this study.

\section{CONCLUSION}

Four out of 100 pregnant women could develop preeclampsia. Pregnant women who are less than 20 or more than 29 years old or who have a history of UTI or a positive roll-over test are more likely to develop preeclampsia. In addition, the roll-over test has a poor sensitivity if done in women in their 20 weeks AOG. More studies are warranted to explore the improvement of its predictive value in other AOG.

\section{Statement of Authorship}

All authors approved the final version submitted.

\section{Author Disclosure}

All authors declared no conflict of interest.

\section{Funding Source}

This paper was funded by the Department of Science and Technology and the Philippine Council for Health Research and Development.

\section{REFERENCES}

1. Department of Health Epidemiology Bureau, The 2011 Philippine Health Statistics [Internet]. 2016 [cited 2016 Sep]. Available from http://www.doh.gov.ph/sites/default/files/publications/ PHS2011_ edited.pdf.

2. Center for Health Development, CARAGA Region Health Profile 2011 [Internet]. 2011 [cited 2016 Sep]. Available from http://issuu. com/sergiebunani/docs/chd-CARAGA_health_profile_2011.

3. National Nutrition Council, CARAGA Region History and Geography [Internet]. ND [cited 2016 Nov]. Available from http:// www.nnc.gov.ph/2-uncategorised/322-CARAGA-region-historyand-geography. 
4. Eiland E, Nzerue C, Faulkner M. Preeclampsia. J Pregnancy. 2012; 2012:586578.

5. Turner JA. Diagnosis and management of pre-eclampsia: an update. Int J Womens Health. 2010 Sep; 2:327-37.

6. Task Force on Hypertension in Pregnancy, Hypertension in Pregnancy [Internet]. 2013 [cited $2016 \mathrm{Nov}$ ]. Available from https://www.acog. org/Clinical-Guidance-and-Publications/Task-Force-and-WorkGroup-Reports/Hypertension-in-Pregnancy.

7. Sibai BM. Maternal and uteroplacental hemodynamics for the classification and prediction of preeclampsia. Hypertension. 2008 Nov; 52(5):805-6.

8. Sibai B, Dekker G, Kupferminc M. Preeclampsia. Lancet. 2005 FebMar; 365(9461):785-99.

9. Duckitt K, Harrington D. Risk factors for pre-eclampsia at antenatal booking: systematic review of controlled studies. BMJ. 2005 Mar; 330(7491):565.

10. Ros HS, Cnattingius S, Lipworth L. Comparison of risk factors for preeclampsia and gestational hypertension in a population-based cohort study. Am J Epidemiol. 1998 Jun; 147(11):1062-70.

11. Xia Y, Kellems RE. Is preeclampsia an autoimmune disease? Clin Immunol. 2009 Oct; 133(1):1-12.

12. Bezerra Maia E Holanda Moura S, Marques Lopes L, Murthi P, da Silva Costa F. Prevention of preeclampsia. J Pregnancy. 2012; 2012(1):435090.

13. Park HJ, Shim SS, Cha DH. Combined Screening for Early Detection of Pre-Eclampsia. Int J Mol Sci. 2015 Aug; 16(8):17952-74. doi:10.3390/ijms160817952.

14. Cunningham FG, Leveno KJ, Bloom SL, et al. Williams Obstetrics, 24th ed. New York: McGraw-Hill Education; 2014.

15. Department of Health, Maternal Deaths by Main Cause [Internet]. 2013 [cited 2016 Nov]. Available from http://www.doh.gov.ph/ node/1484.

16. Conde-Agudelo A, Villar J, Lindheimer M. World Health Organization systematic review of screening tests for preeclampsia. Obstet Gynecol. 2004 Dec; 104(6):1367-91.

17. Meher-Un-Nisa, Aslam M, Ahmed SR, Rajab M, Kattea L. Impact of Obesity on Fetomaternal Outcome in Pregnant Saudi Females. Int J Health Sci. 2009 Jul; 3(2):187-95.
18. Syngelaki A, Bredaki FE, Vaikousi E, Maiz N, Nicolaides KH. Body mass index at 11-13 weeks' gestation and pregnancy complications. Fetal Diagn Ther. 2011; 30(4):250-65.

19. Sohlberg S, Stephansson O, Cnattingius S, Wikstrom AK. Maternal body mass index, height, and risks of preeclampsia. Am J Hypertens. 2012 Jan; 25(1):120-5.

20. Marshall GW, Newman, RL. Roll-over test. Am J Obstet Gynecol. 1977; 127(6), 623-5.

21. Ghojazadeh M, Azami-Aghdash S, Mohammadi M, Vosoogh S, Mohammadi S, Naghavi-Behzad M. Prognostic risk factors for early diagnosing of Preeclampsia in Nulliparas. Niger Med J. 2013 Sep; 54(5):344-8.

22. Lamminpaa R, Vehvilainen-Julkunen K, Gissler M., Heinonen S. Pre-eclampsia complicated by advanced maternal age: a registry-based study on primaparous women in Finland 1997-2008. BMC Pregnancy Childbirth. 2012; 12:47.

23. Liu X, Ruan Y, Liu Y, Zhang W. Relationship between maternal age and hypertensive disorders in pregnancy. Zhonghua Yi Xue Za Zhi. 2015 Jan; 95(1):19-22.

24. Wallis AB, Saftlas AF, Hsia J, Atrash HK. Secular trends in the rates of preeclampsia, eclampsia, and gestational hypertension, United States, 1987-2004. Am J Hypertens. 2008 May; 21(5):521-6.

25. Johnson EK, Urinary Tract Infections in Pregnancy [Internet]. nd [cited 2016 Sep]. Available from http://emedicine.medscape.com/ article/452604-overview.

26. Minassian C, Thomas SL, Williams DJ, Campbell O, Smeeth L. Acute maternal infection and risk of pre-eclampsia: a population-based casecontrol study. PLoS One. 2013 Sep 3; 8(9):e73047.

27. PeckTM.A simple test for predicting pregnancy-induced hypertension. Obstet Gynecol. 1977 Nov; 50(5):615-7.

28. Mohamed K, Lasiende OO. The roll-over test is not of value in predicting pregnancy induced hypertension. Pediatr Perinat Epidemiol. 1990 Jan; 4(1):71-5.

29. Marcopito LF. Roll-over test in primigravidae attending a public primary care service. Sao Paulo Med J. 1997 Sep-Oct;115(5):1533-6. 